\title{
The Necessity of Clinical Legal Education in University Law Schools: A UK Perspective
} James Marson, ${ }^{*}$ Adam Wilson** and Mark Van Hoorebeek***

\section{Introduction}

Few law schools within the United Kingdom (UK) university sector have integrated clinics established as legal practices that offer live client work to the student body. Clinical legal education is becoming increasingly popular within the sector as it provides numerous advantages to the student cohort and establishes an opportunity for the students to gain important practical experience, whilst enabling them to offer a valuable service to the local community.

This paper proposes that the expansion and subsequent unbridling of the provision of a law clinic in the sector will provide the students with the skills necessary of graduates in the increasingly corporate, commercially motivated, UK university sector. Secondly, it provides a basis for the rationale of a movement in funding bands, a study which is being undertaken by the Higher Education Funding Council for England over the proceeding three years, in consequence to the increasing costs involved to the institutions. This increase in funding, coupled with a determination from the institution and case study evidence as presented in this paper, will hopefully propel clinical legal education to the forefront of undergraduate legal studies in the UK. Clinical legal education is a method of improving the student experience and offers various advantages if integrated fully into the university administrative set up. Such views have been given rigorous academic coverage, however this paper further analyses the academic benefits passed on to the student populace, in relation to the potential advantages to UK universities.

\footnotetext{
* Senior lecturer in Commercial Law, Sheffield Hallam University, Department of Law.

** Senior lecturer, Sheffield Hallam University, Department of Law.

*** Lecturer, University of Derby, Department of Law.
} 
Clinical legal education (CLE) has been a concept long provided in institutions in the United States (US) and is increasingly being focused upon in both the Western (Bradney 1992; ${ }^{1}$ Dickson 2000; ${ }^{2}$ and Grimes 1995) ${ }^{3}$ and developing worlds (Iya 2000) ${ }^{4}$ as a fundamental aspect of the undergraduate law students' education. In the UK, whilst such skills have been addressed to varying degrees through mock court and mooting sessions, and the research skills necessary to acquire information through library exercises, the skills of communication with clients, ethical considerations in practice and the ability to put legal education into practical situations have been ignored. This has occurred (amongst other reasons) because of a lack of available expertise, funding, resources, time and accessibility. Despite these limitations universities have began a process of incorporating clinics into their academic framework notwithstanding the higher costs involved, since they see these costs as counter-balanced by a unique learning experience which offers a competitive advantage against similarly placed institutions.

This paper begins by outlining the necessity for CLE in UK law schools and how this will become commonplace and may even become a pre-requisite for full exemptions from professional bodies including the Law Society. It then offers an insight into the working of a law clinic in a university law school in the UK and the benefits and potential offered to students and the institution itself. The paper further highlights how a movement towards CLE may assist in the contentious study undertaken by the Higher Education Funding Council for England (Hefce) over the next three years regarding the funding of undergraduate students and the possible movement in the banding of funding - an initiative which is fundamental to the funding of law clinics and possibly the survival of these university departments. The paper concludes by assessing the implications of CLE to the student and institution with regard to the current structure of legal education and establishes the significant benefits of live client work for law students and the institution.

\section{Necessity for a clinical approach to legal education}

Recent evidence has demonstrated the continuing need for CLE and how universities have to continue to take a serious and proactive stance to this form of pedagogic instruction. Clinical legal education has been seen as providing students with an understanding of the legal environment which awaits them upon graduation and as a means to instil professional values and a sensitivity to the concept of justice. ${ }^{5}$ However, research has highlighted the limitations of clinical education and in particular whether the skills and attributes learned under clinical models actually transfers effectively to the professional world. ${ }^{6}$ Research therefore continues to be a necessary component of the concept of CLE to ascertain whether it does offer the skills and insight into a practical vision of legal practice which classroom based education fails. Clinic is however generally considered to be of value to the student and institution if undertaken seriously and rationally, with a focus on

1 Bradney, A. (1992) "Ivory towers or satanic mills: choices for university law schools" 17 Studies in Higher Education 5.

2 Dickson, J. (2000) "Clinical legal education in the 21st century: Still educating for service?” International Journal of Clinical Legal Education, November 33.

3 Grimes, R. (1995) "Legal Skills and Clinical Legal Education" Web Journal of Current Legal Issues 3.

4 Iya, P. F. (2000) "Fighting Africa's poverty and ignorance through clinical legal education: Shared experiences with new initiatives for the 21st Century" International Journal of Clinical Legal Education, November 13.

5 MacCrate, R. (2004) "Yesterday, Today and Tomorrow: Building the Continuum of Legal Education and Profesional Development" Clinical Law Review, Vol. 10, Spring.

6 Binder, D. A. and Bergman, P. B. (2003) "Taking Lawyering Skills Training Seriously" Clinical Law Review, Vol. 10, Fall 301. 
the adoption of a real (albeit not-for-profit) law firm, and with the academic ability to extract a theoretical base from the practical experience. It is the very nature of this type of education propelling the students as actors in the legal process rather than mere observers, which enables the full benefits of CLE to be extracted, reflected upon, and re-invested into the student cohort.

The benefits of CLE have been witnessed by the handful of university departments with a system of such education in place. ${ }^{7}$ Historically, universities were established on an academic basis with a focus on theory and critical discourse, however law students require exposure to a more practical form of education and clinics fulfil this criteria. The role and weight of live-client clinical work within the curriculum has been noted and discussed in previous literature (for an interesting discussion see Tarr 1993). ${ }^{8}$ Practical experience gained from work in 'real life' situations has been demonstrated to motivate students and to invigorate their appetite for legal practice, particularly as students have had to focus their attention on the needs of the commercial law sector which is ever more competitive. This focus on the necessity for "commercially focused"9 graduates has been highlighted by leading law firms which have observed "We firmly believe that the closer to real practice and the more realistic training is the more effective it will be". ${ }^{10}$

This commercial focus has been reiterated at a governmental level through the Lord Chancellor's Advisory Committee on Legal Education and Conduct in its Consultation Paper, Review of Legal Education - The Initial Stage. The report makes explicit reference to both the relevance of intellectual and personal skills, and the importance of seeing law in its operational context. ${ }^{11}$ This can be best gauged and assessed in the University setting where the students' learning is paramount. The students do often gain experience in the vacations through work experience at law firms but this is often intermittent and unstructured. Whilst the larger firms do seek to educate and lead the students in their learning, many students identify that they often feel 'used' and even a source of 'cheap labour'. The university can offer the structure that would satisfy the need for education along with the ability for live client work that also provides an invaluable insight into legal practice beyond academic debate.

\section{Live client work: An empirical insight}

CLE provides a learning experience that is difficult to replicate in any classroom setting. With the benefit of academic guidance and structure, an ability to instil values into the students' practice of law, and exposure to real clients with problems which are beyond mere textbook exercises, the students learn key skills and are encouraged to reflect on their experience and their role in the advice process. All students at the case study institution were provided with 'lawyering' skills through compulsory mooting sessions. These involved mock courtroom situations, senior academics acting as judges and arbiters, and a competitive and practical element being added through judging and prizes awarded by local law firms. These skills are vital to increase experience, raise confidence, and offer the students an insight into how the law is actually different in practice to that learned through textbooks.

7 Recent survey figures demonstrate that $43 \%$ of UK universities (90\% of all universities responded) provide students with some form of Law Clinic education, and a further $17 \%$ expressed an intention to provide the service in the future (Browne, S (2000) "A Survey of Pro Bono Activity by Students in Law Schools in England and Wales" Solicitors Pro Bono Group, London).
8 Tarr, N (1993) "Current issues in clinical legal education” 37 Howard Law Journal 31.

9 Legal Week Spring 2004.

10 Firth, S. (2004) Linklaters trainee partner Legal Week Spring 2004.

11 ACLEC (1994) Review of Legal Education - The Initial Stage, ACLEC, p.11. 
Beyond these skills is the awareness of real life advice and an ability for the students to gain experience of dealing with people with problems - and the consequences of these problems. Students advising clients are exposed to the emotion faced by clients, an awareness of their obtaining the relevant facts from the client and focusing their advice on areas of law where the client has a legal challenge; a sense of responsibility to be honest to the client - even where this may involve informing clients of outcomes which may be unpopular; and an appreciation of the pressure and dedication which is required of lawyers. All of these elements contribute to the professionalism which students are expected to demonstrate when they train and begin to practice, and as such they are required to be introduced as soon into the students' education as possible.

Many of the above elements may be a consequence of other modules studied and identified by the variety of learning outcomes as required by bodies such as the Quality Assurance Agency for Higher Education (QAA), but only the exposure in a controlled environment provided by a law clinic in a university setting can offer the rigorous legal practice experience so valuable to law students. The QAA, a body established to maintain standards in university education and to offer guidance to ensure universities achieve the best possible service to their student cohort, has identified the necessity for experiential learning and the strengths of an education which is complemented by legal practice. ${ }^{12}$ This approach to quality is underpinned by the important lessons available in a live law clinic and is where the student can begin practicing the skills expected of lawyers - professional codes of practice, expected behaviour whilst training or on vacation placement, the relevant forms and deadlines for claims, and fundamentally, whether a career as a lawyer is what they would like to pursue. Such skills are essential to future practitioners and to have these instilled at as formative a stage as possible is likely to produce better equipped and more successful law graduates. If left until the professional training is studied (Legal Practice Course or Bar Vocational Course), or left largely unstructured in the plethora of courses available at undergraduate level, the student may find that practice is alien to the academic nature of their previous study and any poor habits formed may leave them disadvantaged in the highly competitive market they may wish to enter.

\section{The case study law clinic}

CLE is vital in a university's holistic approach to legal instruction as it offers the combination of both practical and theoretical bases, along with the structure of protecting and nurturing the students' development. However, such a view must be assessed through an examination of how law clinics work in a practical environment. The case study institution is a large, new university offering a variety of law degrees and instruction at undergraduate and post-graduate level. It has established CLE as a fundamental aim for the past ten years and the provision of a law clinic has grown since. The study involved the cohort of students in the 2003/04 academic session, twenty of whom successfully completed the module, and this section outlines the method of legal instruction adopted by the institution, the key skills identified and emphasised within the unit, the variety of legal cases undertaken by the law clinic team, and the students' participation and self-evaluation in this legal practice.

12 See www.qaa.ac.uk/public/Cop/COPplacementFinal/contents.htm. 


\section{Quality issues in advice at Law Centres}

From the 1st April 2000 the former civil legal aid board was replaced by the Community Legal Service (CLS). The CLS was established to create networks between advice funders, such as local authorities, and suppliers. The avowed aim was to view regional provision of advice holistically to ensure the widest possible access to information and advice. By creating links and networks between advice providers the potential client had the tools to identify the provision of legal advice in the region, and choose the advisory service most appropriate to their needs. The system also enabled the advisory service in the region to keep abreast of the advice available at other centres so that a client could be referred or signposted to another service provider if this was more appropriate. The overriding concern was that all the advice experience and expertise was made as transparent and as available as possible, so as to be as inclusive to all involved in the process. The best quality advice, to those who required free-to-access legal advice and representation, was the CLS's aim.

Access to advice is, however, only a fraction of the equation. Potential clients naturally want assurance that the advice provider operates satisfactory procedures and proffers competent advice. To provide such reassurance the CLS has developed a number of quality marks to assist in the quality process, by providing evidence of the levels of advice offered at an advice centre. This is further supplemented by quality standards being published of the areas of law which are offered - such as housing, welfare, employment and the other main areas of advice required by potential clients. There currently exist quality marks at the various levels of expertise. The hierarchy of quality of advice are as follows: Information, General Help and Specialist Help.

The Quality Mark in Information essentially entails being able to supply referral material, such as leaflets, and to provide access to CLS information or access to its web page. Such limited assistance would not fulfil the educational purpose of a clinic and hence shall not be considered further.

The Quality Mark in General Help typically offers information and advice to a client to help them resolve their problem. The advisor (in this situation the student) will diagnose the problem, explain available options and identify further action which the client may take. In terms of a law clinic there shall also be assistance via drafting letters and any court forms. The case study law clinic retains a Quality Mark in General Help. Once the mark has been awarded it may be displayed at the clinic and upon stationary. It is suggested that this is the most appropriate quality mark for most law clinics.

The final potential quality mark lay in Specialist Help. This requires particular expertise in a specific field and may cover a particularly complex problem or a request for representation in court. The Specialist Quality Mark is a prerequisite to an institution potentially being able to secure public funding for a client. In theory there is no prohibition on clinics obtaining such a Quality Mark. ${ }^{13}$ There are, however, numerous practical constraints. For example, a clinic may not be able to secure sufficient quantities of cases, in a particular field, to develop or provide evidence of specialised help. Equally, teaching staff may not have sufficient time to retain specialised advocacy skills.

All quality marks require clinics to adhere to stringent procedures established by the CLS. The CLS shall, at regular intervals, perform an audit to ensure that adequate standards are being retained. The quality award is advantageous in showing that satisfactory quality processes have

13 Northumbria law clinic, for example, retains Quality Marks in Housing, Welfare Benefits and Employment. Such Quality Marks are only appropriate for substantial, developed clinics but demonstrate the route which law clinics may take. 
been achieved and maintained. Clinical legal education may, potentially, cover extremely disparate fields of law for example housing, employment, consumer, family, welfare, personal injury, criminal injuries claims and commercial work. ${ }^{14}$ Criminal appeals may also be covered. In short, the particular emphasis of the clinic is dependent upon the expertise and stance of the clinic staff.

\section{Typical advice at case study clinic}

Legal advice covers various jurisdictions of law and naturally derive from the clients' needs. Law clinics however have to be selective in offering the advisory service to clients, whilst also recognising their key role as instructing and nurturing the student cohort. Law clinics in the US have established links between CLE and the advice service and consequently can frequently offer a more in-depth service with a greater range of legal services. The UK, whilst attempting to follow this mode, also has been slower to fully adopt this method of practical integration into their law schools and this can be reflected in the advice service that is offered. The case study law clinic offers particular expertise in personal injury, criminal injuries compensation, housing and consumer disputes. These it was considered offered the widest range of legal issues and would expose the students to a variety of clients and scenarios. However, whilst the student's education is vital in this context, the advisory service must also be taken very seriously. The legal same obligations to the client exist for the law students and law firms alike, and part of the CLS partnership scheme requires that the client receives the best possible, and most appropriate, advice. As such, legal advice providers are now part of a network and prior to assuming control of a file, it is essential to ensure that the clinic is the most appropriate advice agency. Due consideration further must be given to possible trade union funding, legal expenses insurance and public funding. If the client could receive funding from an agency (for example a trade union) which would also provide guidance, time and access to legal professionals that may potentially provide a better service for the client, this must be the primary concern of the clinic. This aspect of ethics is also considered when the practical issues of costs and access to private practice are undertaken. The students' education must include the realisation that the client has to be the priority in all advice work and consequently referrals or signposting is in the best interests of the client.

In each scenario where the clinic takes legal instruction, the situation poses unique learning opportunities for students. For example, one recent case concerned a criminal injuries claim for a client who had suffered post traumatic stress following a situation perceived as life threatening. The law was relatively straightforward in this instance and enabled the students to research the issues and create a formula for advice. The actual case, however, and the issues surrounding the treatment of the client and the remedies available caused students to feel aggrieved for the inadequate levels of compensation obtainable for such claims. The students in this situation began to realise the distinction between legal rights and access to what they might perceive to be justice. The lessons learned here were interesting in that injustice in CLE has a real face, the students develop the skills to inform clients of the limits of the redress which they have, and a key skill was highlighted to the student lawyers in the necessity to learn to manage their own emotional reactions.

The typical advice of this law clinic also highlighted a skill which can be difficult to fully develop in a classroom situation. In law schools the typical education is separated into categories of law (for example contract, tort, criminal law and so on) where the students learn how to advise clients in

14 The case study Law Clinic has, in recent years, successfully advised in relation to each of these fields. 
their legal rights. In the real world, evidently, the advisors cannot expect the client to outline the legal problem and hence the advisor has to extract the necessary information and identify the area of law applicable. A recent personal injury file embodied the principle that legal cases cannot be neatly divided into distinct areas of law. A client had, prior to instructing the law clinic, been pursuing a personal injury claim for numerous years together with issues of land law and limitation periods. This provided many useful issues for the students to reflect on, and the requirement to identify the relevant facts quickly and professionally - emotionally distancing themselves from the client. These skills enabled the law clinic to utilise client cases to guide the students through their development as potential lawyers which further enabled law clinic staff to focus the teaching and instruction of the students.

\section{Method of teaching and instruction}

Cases, as identified above, have enabled established law clinics to develop methods to instruct and guide students as to the key skills which lawyers have to possess. This is vitally important as it transcends the textbook world of academic instruction to enable students to identify the distinction between legal research and paperwork, with the skills needed to advise clients. CLE has created and re-formulated these methods of teaching, and whilst there are differences between law clinics in regions of the world (as noted in the following sections), there exist approaches common to many clinical programmes, certainly within England and Wales.

Law schools typically have modules structured to provide a series of lectures, supplemented by seminars, to instruct students on the various points of law. The seminars range in sizes from groups of up to 20, to discussions between the lecturer and small numbers of students. Law clinics are slightly different to this method of teaching due to the presence of the practical base. Law clinics are established as a law firm which has areas of expertise and outlines to clients in which areas advice can be provided. These firms tend to be relatively small in structure ${ }^{15}$ and as with any professional legal service offering advice, the law clinics have allocated at least one professionally qualified supervisor. Due to the restraints of the legal service available, the time restraints and restraints as to the level of competency available at the clinic, potential clients are interviewed to ascertain their suitability to receiving advice, and of course to attempt to make the law service as beneficial as possible to the students. To be as inclusive as possible the students are involved in the interview process of prospective clients who have applied to the clinic for assistance. The students decide, in consultation with their supervisor at the law clinic, which files the clinic can progress. If the client's case is not suitable the students assist in explaining why this to the client, and involve themselves in the referral or signposting of the client. This assists in the identification of suitable cases for the students and it further ensures the students are aware of the help and assistance which is available locally. Following the acceptance of the client to the law clinic, the students subsequently assume full responsibility for their files and collectively undertake all the required advice work.

Typically, the student firms meet at weekly sessions to discuss how their files are progressing, and to discuss any issues which may be relevant such as complex questions, ethical issues, or guidance and support from their peers. These firm meetings are essentially student driven, though the exact

15 The law clinic at Sheffield Hallam University, for example, adopts firms of 6. The University of Northumbria's law clinic similarly has firms with between 4-6 students. 
division of work between students and tutor varies from institution to institution and perhaps even between supervisors. ${ }^{16}$ Each active file is reviewed in turn and the details, whilst understanding the issue of confidentiality, can be explored so that important lessons, or a group approach to a specific issue or problem, can be reviewed and used as a learning tool. The students discuss the work that they have undertaken during the previous week, and agree a work plan for the forthcoming week to ensure the students remain focused to their case and enable the firm to be professional in ensuring a speedy resolution to the clients' problems. The supervisor's role at these meetings is largely to guide the discussions to be relevant to the students' learning; to ensure student understanding; and further to guarantee the expeditious treatment of files.

The weekly meetings are vital to ensuring the students discuss important aspects of practical lawyering skills and these meetings are further supplemented by students' participation in a concurrent programme of skills training. Lawyering skills are clearly of great importance. To offer the advice to any client the student first has to have identified the legal problem and researched the issues to ensure the correct and timely advice is provided. Skills' training focuses predominantly on the so called 'DRAIN' skills of Drafting, Research, Advocacy, Interviewing and Negotiation. These skills are developed on a continuous basis through weekly classes which require consideration of key texts on the particular skill being studied. These skills are then put into practice in the file which the student has responsibility for, and are also discussed in the weekly sessions that consider the development of the students' case. Nevertheless, these teaching sessions are never theoretical, or in the abstract as so much of other legal teaching is, but it assumes a practical guise requiring, for example, a particular court form to be drafted or the application of the skill to the students weekly workload in preparation of the clients file. Academic knowledge is thus applied in a practical context.

A further method of instruction which offers a different perspective to the students method of learning is provided through the series of guest lectures ${ }^{17}$ available throughout the year. Students are encouraged to become involved in the series as the lecturers are drawn from local practitioners, from diverse backgrounds, involved in different areas of law, both from public and private law jurisdictions, and it enables the students to interact and gain insights into the world of legal practitioners. The lectures centre on the experience of practicing law, but the lectures also move away from simply an academic exercise on points of law, and increasingly highlight the commercial pressures of legal practice, and the benefits / drawbacks from practice. Students are encouraged to ask questions that have arisen from their own experience of clinic work, and to identify the need for critical reflection of their role as advisor and the justice system as a whole. Academic study, coupled and underpinned by a practical grounding, is the key to this form of teaching and instruction.

16 The case study model advocates extremely active student participation. Students are responsible for chairing firm meetings. Students also act as secretary and are responsible for taking minutes. Students are expected to suggest work plans for the forthcoming week, though guidance from the supervisor may be necessary in this regard.

17 Guest lectures are an integral part of the case study Law Clinic programme. 


\section{Legal skills developed}

It has been demonstrated that the law clinic's education initiative emphasises the 'DRAIN' range of legal skills. The emphasis of these skills is important because of the typical skills backgrounds of the students studying at UK universities, and the tendency of many students entering clinical education to initially conceive of legal skills in a very narrow compartmentalised fashion. For example the skill of drafting legal documents may be viewed as limited solely to writing court and client forms. Advocacy also may be perceived as limited to formal hearings in courts and tribunals where the advisor addresses the court directly. Numerous students express their concern that they have little experience of such skills and this is one of the key elements which CLE covers. CLE not only attempts to instil DRAIN skills in the students, it fundamentally encourages the students to draw upon existing experiences to identify that they do actually posses many of the skills. CLE focuses the students' attention on reflection and critical thought.

It is perhaps apparent that any university modules aspiring to teach such diverse qualities ab initio would be destined to either fail or achieve extremely limited results. Other modules at the case study university do introduce the skills of advocacy and research, but do so as part of other teaching - being ancillary to the module rather than fundamental to it. The advantage of clinical education is that it places these skills central to the entire philosophy of the module. By teaching skills in relation to real, everyday cases, students quickly realise that they already have the basic skills identified in the DRAIN training, and that clinical education seeks to fine tune these in a legal setting.

\section{DRAIN skills identified}

Formal drafting of legal documents is vital to any lawyer and as such this aspect of the students' training very quickly becomes a weekly event in a clinic setting. Students undergo something of a baptism of fire once they realise that any document recorded on file may potentially be viewed by a court, client or another legal advisor. Attendance notes become an exercise of formal drafting. Letters become vital examples of drafting. In addition, students shall almost certainly have to draft witness statements or, at the very least, proofs of evidence, and it is quite likely that formal court documents such as Claim Form (N1) and a Particulars of Claim may also require drafting of the students.

Research is an inherent element of any academic study of law with the emphasis on continual research into statutes and case law being necessary of academics and practitioners alike. Academic modules require the identification, acquisition and comprehension of numerous primary and secondary sources of law. Students should enter clinical education with, at the very least, a competent grasp of research. Clinical education introduces a substantial array of new texts and pushes the student into the unique area of practitioner encyclopaedias and texts. Sources such as Halsbury's Laws of England assume relevance for perhaps the first time and whilst these may not in essence be new skills, they are skills which are applied in new contexts.

One area of the legal training which concerns students more than most is that of advocacy which can result in trepidation and fear. Many students assume it is a skill completely divorced from them because of the prospect of formal presentations and public speaking. In a clinical setting, however, it quickly becomes apparent that advocacy is solely about communicating in a persuasive fashion. In this sense it is a skill nurtured every time the student seeks to persuade someone of their point of view. Advocacy, through CLE, may now be perceived as a daily activity. Speaking to 
a client or writing a letter is advocacy; persuading firm members to pursue a particular line of research is advocacy. It is this emphasis which aids in the students' development. Having established that they already possess excellent advocacy skills, together with years of practical experience, fear is, at least partially, reduced. Students may then reflect on how they have previously set about being persuasive. Such Socratic reflection, drawing on common experience, accelerates learning of advocacy skills. The relatively mundane setting of a file assists in 'grounding' advocacy and continued practice makes this skill 'second nature' to the student who begin to view advocacy as part of their work at the clinic. Guides are then introduced which develop these skills directly as to how the students' experience can be applied in a courtroom. This seems preferable to the more formal setting of a moot where the preoccupation with an abstract or technical academic point seems only to make advocacy more distant and frightening.

All students participate in at least one interview of a client or prospective client. Initially, this feature of clinical education is viewed with a degree of consternation. The students are assisted in this task by furnishing them with a suggested, though flexible, interview plan which helps to alleviate excess anxiety. Role-plays also assist in this regard. Students almost universally express fulfilment at having participated in an interview and the experience is usually enjoyed despite those feelings of anxiety. The ability to listen, under stress, is an essential skill developed during an interview session. Students further learn that engaging in an activity, despite initial anxiety, produces invaluable rewards.

Negotiation is the last of the DRAIN skills and may assume many forms in clinical education. It may involve formal negotiations, for example with a representative of organisations such as the Advisory, Conciliation and Arbitration Service. Negotiation may assume an informal guise such as negotiating a workload for a particular week. Negotiation may be either in verbal or written form and students are taught to be astute to the many different forms that negotiation may assume. Having engaged in any form of negotiation, reflection allows participants to assess how they approached the negotiation. The merits, or otherwise, of their approach may be evaluated with the students encouraged to compare their approach towards negotiation with hypothetical models such as the aggressive, passive and principled negotiation models. Fundamentally, practical experience informs development. Hypothetical models are not taught in an academic abstract manner, which may fail to engage students, but are contrasted to and used to inform personal experience.

\section{Student benefits}

The first, and perhaps salient, benefit of clinical education is that the overwhelming majority of students enjoy the experience and have found it to provide different benefits from classroom study. There are, perhaps, a variety of reasons for this. First, students can see their work directly benefiting a real person and obtain personal satisfaction from impacting positively on someone's life. Second, they can see the vocational, and academic, significance of the skills they are developing. Third, they have been given responsibility and empowerment, which is often alien to students (this is something generally reserved for practicing solicitors), and they feel a duty towards their client. Enjoyment is naturally a desirable end in itself but it also serves the function of ensuring students actively engage with the process of learning. The energy of firm meetings frequently compares favourably to the apathy-induced somnambulism pervasive to more traditional seminars. Active engagement creates an atmosphere conducive to learning which is 
almost infectious amongst the students. A team spirit is achieved where students assist each other rather than viewing others in the class as competition for grades or jobs.

A further benefit is that many students grow in confidence because of the 'close-knit' community of the clinic. By working in small firms a supportive, secure atmosphere is, usually, forged. Students quickly feel at ease with other firm members through sheer exposure and feelings of shared experience. Equally, there is no hiding place in clinical education. Students are required to participate in firm meetings and to develop assertiveness skills required to chair meetings. Students in seminars frequently do not participate in discussions and fail to achieve their potential, but clinics require full participation. It is also evident that academic ability is not necessarily predictive of clinical ability. Many students who are less able academically than their peers thrive in the clinic setting and their confidence blossoms, which turn reflects positively in their other module assessment.

A related, but distinct, feature is that interpersonal skills are nurtured. Students must be able to empathise with a client's perspective and this 'human' aspect is also coupled with the 'commercial' element of the case. This feature assumes salient importance and as such cannot be underestimated. Such facets are typically ignored in an academic exposition of the law. A further benefit of CLE is that it shows the practical relevance of the law studied on other modules. This renews interest in the law programme holistically. Furthermore, by applying the law to an actual case students frequently understand concepts previously less clear to them.

CLE may fundamentally offer tangible benefits for the students as it has the capacity to achieve deep learning - for numerous reasons. First, students must engage in fact analysis. In academic modules students are furnished with a question which requires the law to be applied to a series of distinct facts. In clinical education students are deprived even of a set of coherently presented facts. They must understand the law in sufficient depth to determine for themselves which elements of the client's story are important to the case, and which should be disregarded. In addition, practical problems, as found in clinics, rarely adhere to neat, distinct compartments. A case may require consideration of perhaps company law, land law, tort, civil procedure, professional ethics, evidence, negotiation, drafting and remedies. The ability to forge coherent links between such distinct and diverse elements, and view the cases as often a mixture of different legal jurisdictions, requires clarity of mind.

Of fundamental significance is the fact that students also acquire an understanding of law in context. Legal rights are juxtaposed to practical considerations. Questions of cost and commercial relationships acquire a status at least comparable, if not prevailing, over formal legal rights. Increasingly, law firms are insisting students have an understanding of the commercial aspect of legal practice (beyond impressive grades) and CLE provides this insight. Issues such as access to justice and legal procedures acquire a significance not otherwise encountered or emphasised. Finally, the complex, but fundamental, issue of ethics in legal work is provided. Students are required to have recourse to relevant parts of the Guide to the Professional Conduct of Solicitors 1999 and are presented with the opportunity to consider whether personal ethics require standards which are even more stringent than those imposed by professional bodies. This requires a reflective, critical and analytical approach to their studies which requires a great deal from the students involved in clinics. This in turn provides an education experience which establishes skills that are transferable, and gives an awareness of legal practice which classroom studies (or arguably vacation voluntary work) cannot provide. 


\section{UK and international approach}

As emphasised in the introductory paragraphs to this paper, it was recognised that the UK has only recently, on a relative basis, began seriously considering the value of CLE and practicing this in their law schools. The US, by comparison, has for many years established and refined this form of education which can be witnessed by the breadth and depth of CLE offered. In the case study institution to which this paper has based the majority of its study, predominately the cases heard involve consumer problems and basic, entry-level, contractual disputes. ${ }^{18}$ CLE has grown throughout the educational legal community (as indeed reflected by journals such as this) and can be evidenced in countries as diverse as Abkhazia, ${ }^{19}$ Armenia, ${ }^{20}$ Cambodia, ${ }^{21}$ Mexico, ${ }^{22}$ Mozambique, ${ }^{23}$ Poland, ${ }^{24}$ South Africa ${ }^{25}$ and Turkey ${ }^{26}$ (to name but a few). This international dimension is encouraging and in part demonstrates the seriousness with which educators and practitioners are viewing the necessity for CLE at the undergraduate level. Much research has been conducted on CLE in the US but relatively little elsewhere. It is also the case that the US has taken CLE seriously for a number of years and is therefore a model which other countries are looking towards for guidance and comparison (using it as a benchmarking tool to a certain extent).

The US approach has been significantly more proactive, inclusive and holistic in the provision of CLE which can be witnessed through the details of subject areas as listed in the various US-based directories. ${ }^{27}$ It is also noticeable of the way in which UK institutions trail behind their US counterparts when viewing the provision of CLE by institutions such as Roger Williams University which offers three types of law clinic for student participation, including community justice, criminal defence and disability law jurisdictions. The Community Justice Clinic involves direct client contact, handling a case from beginning to end which includes the interviewing, counselling, investigation, drafting of documents, advocacy and negotiation elements. This ensures all facets of the process of justice are included and gives the student a unique insight into the justice system to which they may wish to enter. The Criminal Defence Clinic enables the student to directly represent clients on matters as diverse as traffic offences, drug possession, domestic violence and disorderly conduct. The Disability Law Clinic focuses on protecting rights in areas of social security, but this further focuses on low-income clients and legal advice in areas including divorce, supervision orders, custody matters and paternity issues. This level of contact with clients, coupled with regular seminars, classes considering legal techniques, and tutor supervision demonstrates an exposure to the legal profession which institutions based in the UK are at present unlikely to be in a position to match. This is, however, a model which progressive institutions in the UK are looking towards, and expansion is the next step following the successful incorporation of CLE law clinics. As a consequence law clinics are being established on a wider basis amongst the

18 Over the years that the law clinic has been established, various cases have been addressed, but the cases most frequently undertaken are those involving consumer disputes. This is due to the time limits involved in UK university law clinics, the availability of supervisors to assist the students, and the CLS partnership which may require the complex cases to be referred to a more appropriate advisory agency.

19 Sokhumi State University.

20 Yerevan State University.

21 Pannasastra University.
22 CIDE Law School.

23 Eduardo Mondlane University.

24 Warsaw University.

25 University of Natal, Durban.

26 Bilgi University, Istanbul.

27 Such as the Clinical Legal Education Association, the Directory of Clinical Legal Educators and Association of American Law Schools, Section on Clinical Legal Education. 
UK university sector than previously undertaken, and they are also being expanded on an intrauniversity basis. Whilst the entire student cohort is unable to participate in the legal practice of their department, it is increasingly being made available to second and third year students to be more inclusive; there is a competitive element to gain entry to the system to ensure the participants benefit from the experience; and the success of the project at the case study institution has led to greater resources being made available from the departmental funds.

One area where there are similarities is on the necessity for student independence, and a studentfocused approach to self directed learning and reflection. The students are encouraged to participate actively in their own educational growth - both personally and professionally - and this is continually assessed to ensure the student understands how to measure their success. This is clearly based on their skills, preparation and presentation of advice to clients rather than whether the client received the advice they were expecting, or whether the client 'won' their case. Reflection, in both the US and UK models, is a key feature of CLE and provides this invaluable learning experience.

\section{Live client work and Hefce assessment of funding}

The second element to the necessity of CLE in UK universities is how it may assist in gaining additional funding for the sector. It may be argued that law schools have often suffered from underfunding compared with other subject areas. The study being undertaken by Hefce is an opportunity to demonstrate how teaching in law schools is different from the other 'arts' subjects - and CLE may be the effective vehicle for the eventual change in funding bands. Hefce is the body that is charged with assessing and distributing the public funds which universities receive for the education they provide. The funding is based on the numbers of students expected at the institution and each student has a monetary value, which when multiplied by the student cohort, is the level of funding received by each university department. The current method of assessing funding levels is based on expenditure as reported by the institution and is further sub-divided on the basis of the nature of the teaching. There are four bands which identifies the level of funding provided to the institution multiplied per student - band $\mathrm{A}^{28}$ is the highest and involves mainly clinical subjects such as medicine and dentistry; band $\mathrm{B}^{29}$ covers laboratory based teaching such as engineering and technology subjects; band $\mathrm{C}^{30}$ involves less expensive laboratory work, fieldwork dependent subjects and drama; and band D, ${ }^{31}$ the lowest band, includes all other subjects and, importantly for this paper, law. It applies to law due to the assumption of the subject being taught wholly in lecture theatres and seminars / tutorials which is increasingly unrealistic. This funding has led to concerns over the feasibility of providing free education in the sector and may also be unrealistic due to the changing nature of university education. Due to these concerns it was decided at its meeting in December $2003^{32}$ that Hefce would review its methods of funding and as a consequence would adopt a cost-based approach - the Transparent Approach to Costing model. This study is estimated to take three years to complete and as such it is proposed that the use of law clinics and exposure to live client situations would not only assist the students in their learning

28 This band has a weighting of 4.

29 This band has a weighting of 1.7.

30 This band has a weighting of 1.3 .

31 This band has a weighting of 1 - in the 2004/5 session this is estimated to be at a level of $£ 3,400$ per full-time student.

32 As published on Tuesday 23rd December 2003 www.hefce.ac.uk/news/hefce/2003/funding.asp. 
but also aid in the movement of the subject into a more realistic band which would ease the financial burdens experienced by law departments in the sector.

This debate has already begun and has led to discussions by groups (see Burridge 2003) ${ }^{33}$ which argue the nature of law teaching necessitates higher funding and additional resources which are peculiar to legal training and should not be banded with other social sciences. The requirement of law reports, statutes, subscription to various paper and electronic databases and journals (especially Lexis-Nexis and Westlaw), and of course teaching practical lawyer skills involves higher costs than traditional band D subjects, and the law clinics are essential to ensure the holistic and rounded approach to the students' educational experience. These resources are not simply referred to but have to be 'used' and applied which is more akin to a workshop or laboratory situation than simply a tutor/student dialogue in a seminar room.

\section{Institutional benefits}

If these clinics are established, or are amongst the strategic planning of university law departments, the benefits for the institution are transparent and tangible. The funding assessment being conducted is likely to recognise the unrealistic nature of band D funding and the distinct and unique teaching and the variety of learning methods required at law schools. The use of case law; law reports; the necessity for access to up-to-date materials in dynamic areas such as European Union and employment law; the necessity for research skills, advocacy and effective written and oral communication, and the interactive nature of legal education, which will be underpinned by the expansion of live client education in law clinics, will result in a strong case for movement into band $\mathrm{C}$ with its criteria of fieldwork and laboratory-type education. CLE, and the practical nature of law, is absolutely essential to the students' development and as such is a compulsory component in the teaching of law undergraduates. The increase in funding will generate a greater opportunity for legally-qualified staff to be retained by the institutions which can then be employed in law clinics which will also enable the expansion of the service to the student body and local community.

Links between the university, local community and local law firms will benefit from the law clinics due to the increased interaction between the not-for-profit legal service being provided (often, as with the case study law clinic, regulated to provide quality generalist advice through the CLS Commission) and the individuals who utilise the advice agency. Law firms also witness the benefit of this type of legal training and the important skills instilled in the graduates which makes students with this experience more employable and successful in the sector. As employability is increasingly being contained in higher education statistics, league tables and university prospectuses, law clinics offer only positive effects for the institutions with the capacity and desire to establish them.

33 Burridge, R (2003) 'Reassessing Band Funding for Law: A Discussion Paper' www.ukcle.ac.uk/resources/banding.html. 


\section{Conclusion}

This paper has sought to demonstrate the necessity of a clinical approach to legal education, and reasons why such an approach must be taken by institutions to ensure future law graduates are being given the required training and skills in a structured environment. The case study has outlined the provision of live client work in a university institution and how it benefits all the actors involved through skills, training, experience and an appreciation of working as a lawyer. No simulation or class-room based session can offer the student a true insight into the pressures and, at times, exhilaration of legal practice, and this experience can only assist in producing better prepared trainee lawyers. Institutions cannot offer the service without a complete appreciation of the time and costs involved, but this paper has aimed to establish how it works in a modern UK university, the wider implications for all publicly funded university law departments, and the complementary benefits for the students and institution. CLE is becoming an option that students will be looking towards when choosing their education provider, and with the advent of top-up fees and students contributing financially to their own education, institutions without this option may become increasingly disadvantaged. 